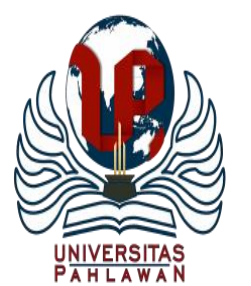

Jurnal Abdidas Volume 1 Nomor 5 Tahun 2020 Halaman 339 - 344

JURNAL ABDIDAS

Community Development Service on Educational and Health Sciences

http://abdidas.org/index.php/abdidas

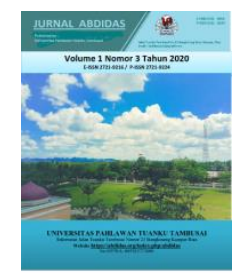

\title{
Pemanfaatan Alat Peraga Matematika sebagai Media Pembelajaran di SD Oebola Di Nusa Tenggara Timur
}

\author{
Yohanes O. Jagom ${ }^{1}$, Irmina V. Uskono ${ }^{2}$, Aloysius J. Fernandez ${ }^{3}$ \\ Universitas Katolik Widya Mandira, Nusa Tenggara Timur, Indonesia ${ }^{1,2,3}$ \\ E-mail : jagom2020@ unwira.ac.id ${ }^{1}$, veniuskono@yahoo.com ${ }^{2}$, fndz1586@ gmail.com $^{3}$
}

\begin{abstract}
Abstrak
Alat peraga matematika merupakan media pembelajaran yang dapat membantu siswa dalam mengkongkritkan konsep yang abstrak sehingga menjadi mudah untuk dipahami. Oleh karena itu guru wajib dituntut untuk mampu menghasilkan alat peraga sebagai media pembelajaran yang dapat meningkatkan minat dan motivasi belajar dari siswa. Hal ini perlu dilakukan guru agar mampu memanfaatkan media pembelajaran yang sederhana dalam mentransferkan materi ajar sehingga siswa mampu menangkap dan memahami materi yang disampaikan dengan baik sehingga tujuan pembelajaran yang dirancang dapat tercapai. Tujuan dari pengabdian ini untuk membantu guru-guru dan siswa agar dapat memanfaatkan alat peraga matematika dalam pembelajaran. Metode yang digunakan berupa metode praktek, diskusi serta observasi. Kegiatan pengabdian ini dilaksanakan di SD Inpres Oebola Dalam Kecamatan Fatuleu Kabupaten Kupang Nusa Tenggara Timur. Dengan sasaran peserta guru-guru dan siswa. Pelaksanaan kegiatan pemanfaatan alat peraga matematika sebagai media pembelajaran dapat berjalan dengan lancar sehingga meningkatkan antusiasme dari peserta dengan memberikan berbagai macam respon positif, serta peserta dapat memahami dan menggunakan alat peraga matematika dalam memahami konsep. Oleh karena itu perlu adanya bimbingan dan pelatihan bagi para guru agar mampu menghasilkan media pembelajaran yang baik sehingga mampu diterapkan dalam kegiatan pembelajaran di kelas untuk meningkatkan minat dan mitivasi belajar siswa.
\end{abstract}

Kata kunci: alat peraga matematika, media pembelajaran, konsep matematika

\section{Abstract}

Mathematical props are a medium of learning that can assist students in conspiring abstract concepts so that they become easy to understand. Therefore teachers are required to be able to produce props as a medium of learning that can increase students' learning interest and motivation. It is important to help teachers able to make use a simple medium of learning in transfering the the teaching materials so that students find it easy to catch and understand the materials delivered so the laearning objectives can be aachieved. The aim of this community service is to assist teachers and students to make use mathematical props in learning. The methods used are practice, discussion and observation. This community service was implemented in the Inpres Oebola Elementary School In Fatuleu Subdistrict of Kupang regency, Nusa Tenggara Timur province where the targets were teachers and students. The implementation of the activities of using mathematical props as a learning medium go smoothly so it can increase enthusiasm from participants by providing a wide variety of positive responses and they can understand and use mathematical props to understand concepts. Therefore, it is necessary to provide guidance and training for teachers to be able to produce good learning media to be applied in learning activities in the classroom to increase students' learning interests and motivation.

Keywords: mathematical props, learning media, matematical concep

Copyright (c) 2020 Yohanes O. Jagom, Irmina V. Uskono, Aloysius J. Fernandez

$\triangle$ Corresponding author

Address : Jln. San Juan N0. 01 Penfui. Kupang, NTT

ISSN 2721-9224 (Media Cetak)

Email : jagom2020@unwira.ac.id

ISSN 2721- 9216 (Media Online)

Phone : 085253084334

DOI : https://doi.org/10.31004/abdidas.v1i5.73 


\section{PENDAHULUAN}

Perkembangan ilmu pengetahuan dan teknologi (IPTEK) berdampak pada semua lini kehidupan. Selain perkembangannya begitu pesat, perubahan juga terjadi begitu cepat. Sehingga diperlukan kemampuan dalam memperoleh, mengelolah dan memanfaatkan ilmu pengetahuan dan teknologi tersebut secara proposional. Kemampuan ini membutuhkan pemikiran yang sistematis, logis dan kritis yang dapat dikembangkan melalui peningkatan mutu pendidikan.

SD Inpres Oebola Dalam merupakan salah satu penyelengara pendidikan yang mempunyai tujuan untuk mewujudkan dan mengedepankan pendidikan sebagai pondasi dasar dalam menciptakan sumber daya yang mampu bersaing di era modern saat ini. Hal dasar yang menjadi tolak ukur yaitu guru harus mampu mengimplementasikan proses pembelajaran sesuai dengan kurikulum yang berlaku dengan memanfaatkan setiap sarana dan prasarana semaksimal mungkin. Oleh karena itu guru-guru dituntut untuk sekreatif mungkin dalam menciptakan dan mempersiapkan pelaksanaan pembelajaran.

Namun kenyataannya bahwa para siswasiswi serta guru-guru di SD Inpres Oebola Dalam yang menjadi sasaran kegiatan ini, masih belum mengetahui secara mendalam mengenai pemanfaatan alat peraga matematika dalam kegiatan pembelajaran. Hal mendasar yang menjadi penyebabnya adalah guru belum menggunakan dan memanfaatkan alat peraga dalam kegiatan pembelajaran, selain itu guru belum juga dapat menciptakan pembelajaran yang berkualitas karena sering kali mengalami kesulitan dalam memberikan gambaran kongkrit dari materi yang disampaikan. Sehingga berdampak langsung terhadap kualitas yang dicapai oleh siswa siswi.

Permasalahan seperti ini juga pernah diungkapkan oleh (Susanah, Ismail, \& Astuti, 2016) dalam penelitiannya mengatakan bahwa sebagian besar guru-guru belum mampu menggunakan dan membuat alat peraga agar digunakan dalam kegitan pembelajaran, dan belum semua guru diberikan bekal dalam pelatihan pembuatan alat peraga. Selain itu (Azmi, Sripatmi, Subarina, Amrullah, \& Turmuzi, 2019) mengungkapkan guru sering menganggap bahwa dengan menggunakan alat peraga mengakibatkan pembelajaran menjadi tidak praktis, serta waktu yang dibutuhkan dalam menyelesikan suatu materi menjadi lebih lama.

Kondisi seperti ini akan terus terjadi selama guru masih menganggap bahwa dirinya merupakan sumber belajar bagi peserta didik dan mengabaikan peran dari media pembelajaran. Kontribusi alat peraga dalam pembelajaran dapat merangsang siswa untuk mampu beriteraksi serta aktif dalam mengikuti setiap rangkaian dari proses pembelajaran sehingga dapat meningkatkan motivasi dan minat dari peserta didik tersebut.

Perlu diketahui bahwa fungsi dari alat peraga merupakan sebagai alat bantu yang digunakan untuk menciptakan suasana pembelajaran agar lebih efektif, serta dapat menanamkan kosep-konsep serta mempercepat proses belajar mengajar sehingga siswa tidak merasa bosan dan malas karena penjelasan sudah 
terfokus pada alat peraga yang diperagakan (Rusmawati, 2017). Melalui alat peraga imajinasi siswa dirangsang untuk berpikir aktif serta diharapkan dapat berinteraksi dengan lingkungan belajar secara baik (Binanguan \& Hakim, 2016). Alat peraga mampu menjelaskan materi yang disampaikan sehingga siswa mampu belajar secara mandiri (Hutagaol, Nyama, \& Warkitin, 2019). Dengan menggunakan alat peraga matematika siswa dapat terlibat aktif dalam kegiatan pembelajaran pembelajaran, serta aktivitas mentalnya menjadi lebih hidup sehingga dapat meningkatkan gairah terhadap pembelajaran matematika (Sa'o, Naja, \& Irfan, 2019). Selain itu peranan alat peraga dalam matematika dapat meletakkan ide-ide dasar dari suatu konsep atau teori (Suwardi, Firmiana, \& Rohayati, 2014).

Manfaat dari penggunaan alat peraga dalam pembelajaran matematika menurut (Murdiyanto \& Mahatma, 2014) yaitu dapat meningkatkan minat dan motivasi dalam mempelajari materi matematika serta meningkatkan sikap positif dalam mengikuti setiap pelajaran matematika, Dapat mengkongkritkan materi matematika yang kajiannya bersifat abstrak, Selain itu dapat juga meningkatkan daya ingat siswa sehingga lebih berhasil dalam belajarnya. Selain itu perlu dipahami bahwa perbedaan antara media pembelajaran dengan alat peraga terletak pada fungsinya dan bukan pada substansinya. Suatu sumber belajar disebut alat peraga bila hanya berfungsi sebagai alat bantu pembelajaran saja namun sumber belajar disebut media apabila merupakan bagian dari keseluruhan proses atau kegiatan (Nasaruddin, 2015).
Berdasarkan urain tersebut maka perlu diperhatikan kegunaan dan manfaat dari alat peraga dalam kegiatan pembelajaran matematika sehingga siswa mampu lebih termotivasi dalam mengikuti setiap proses pembelajaran serta meningkatkan minat siswa dalam mengikuti kegiatan pembelajaran yang memberikan dampak positif bagi guru sehingga mampu menciptakan proses pembelajaran yang lebih efektif serta guru mampu lebih kreatif lagi dalam membuat alat peraga sebagai media pembelajaran yang dapat meningkatkan minat siswa.

Berangkat dari permasalahan tersebut maka dipandang perlu untuk melaksanakan kegiatan pengabdian pemanfaatan alat peraga matematika sebagai media pembelajaran di SD Oe Bola Dalam.

Adapun tujuan pelaksanaan pengabdian ini yaitu:

a) Memberikan pelatihan cara penggunaan alat peraga sebagai media dalam proses kegiatan pembelajaran.

b) Memberikan sumbangsi pengetahuan bagi guru-guru serta siswa siswi SD Oebola Dalam tentang cara pembuatan dan penggunaan alat peraga matematika.

c) Mengetahui respon guru dan siswa terhadap kegiatan pengabdian yang dilakukan.

\section{METODE}

Metode yang digunakan untuk mencapai tujuan kegiatan pelaksanaan pemanfaatan alat peraga matematika sebagai media pembelajaran di SD Inpres Oebola Dalam yaitu diskusi, penyuluhan dan pendampingan. Metode tersebut 
teringerasi pada bebeberapa tahapan pelaksanaan kegiatan yaitu; a) persiapan; mengidentifikasi permasalahan yang dihadapi oleh sekolah, mengidentifikasi jenis alat peraga yang dibutuhkan, mengidentifikasi sarana dan sumber belajar yang terdapat dilingkungan. b.) pelaksanaan; memaparan materi tentang pembuatan alat peraga dan penggunaannya dalam pembelajaran matematika, melaksanakan pelatihan dalam membuat alat peraga dalam pembelajaran matematika, simulasi cara menggunakan alat peraga yang dibuat dalam pembelajaran matematika dan c) evaluasi pelaksanaan kegiatan; memberikan angket kepada peserta setelah pemaparan dan pelatihan pembuatan alat peraga pembelajaran matematika berakhir, mengoreksi hasil pelatihan dalam membuat alat peraga pembelajaran matematika, merefleksi simulasi alat peraga yang dibuat dalam pembelajaran matematika.

\section{HASIL DAN PEMBAHASAN}

\section{Pelaksanaan Kegiatan}

Kegiatan Pelatihan Pemanfaatan Penggunaan Alat Peraga Matematika Sebagai Media Pembelajaran di SD Oebola Dalam di laksanakan dalam waktu 3 (tiga) hari yang dibagi dalam 3 (tiga) kegiatan. Kegiatan dimulai dari pukul 09.00 sampai 11.00 WITA yang dihadiri oleh 58 peserta. Kegiatan ini dimulai dari hari pertama (pukul 09.00-11.00 WITA) yaitu mendemonstrasikan alat peraga Mistar Hitung Bilangan Bulat dan Papan Napier. Selanjutnya hari kedua (pukul 09.00-11.00 WITA) mendemonstrasikan alat peraga Perkalian Metode Kotak dan Dakota, dan hari ketiga (pukul 09.00-11.00 WITA) mendemonstrasikan alat peraga Papan Berpaku dan Perkalian Kanada. Pengalokasian waktu dapat dilihat pada tabel 1 . Berikut.

Tabel 1. Pelaksanaan Kegiatan

\begin{tabular}{|l|l|lr|}
\hline \multirow{2}{*}{ No } & \multicolumn{3}{|c|}{ Jadwal Kegiatan } \\
\cline { 2 - 4 } & $\begin{array}{l}\text { Sub-kepala } \\
\text { Kolom }\end{array}$ & \multicolumn{3}{|c|}{ Sub-kepala Kolom } \\
\hline 1 & Hari Pertama & $\begin{array}{l}\text { Mendemonstrasikan } \\
\text { peraga } \text { alat } \\
\text { Bilangan Bulat dan Papan } \\
\text { Napier }\end{array}$ \\
\hline 2 & Hari Kedua & $\begin{array}{l}\text { Mendemonstrasikan alat } \\
\text { Peraga Perkalian Metode } \\
\text { Kotak dan Dakota }\end{array}$ \\
\hline 3 & Hari Ketiga & $\begin{array}{l}\text { Mendemonstrasikan alat } \\
\text { peraga Papan Berpaku dan } \\
\text { Perkalian Kanada. }\end{array}$ \\
\hline
\end{tabular}

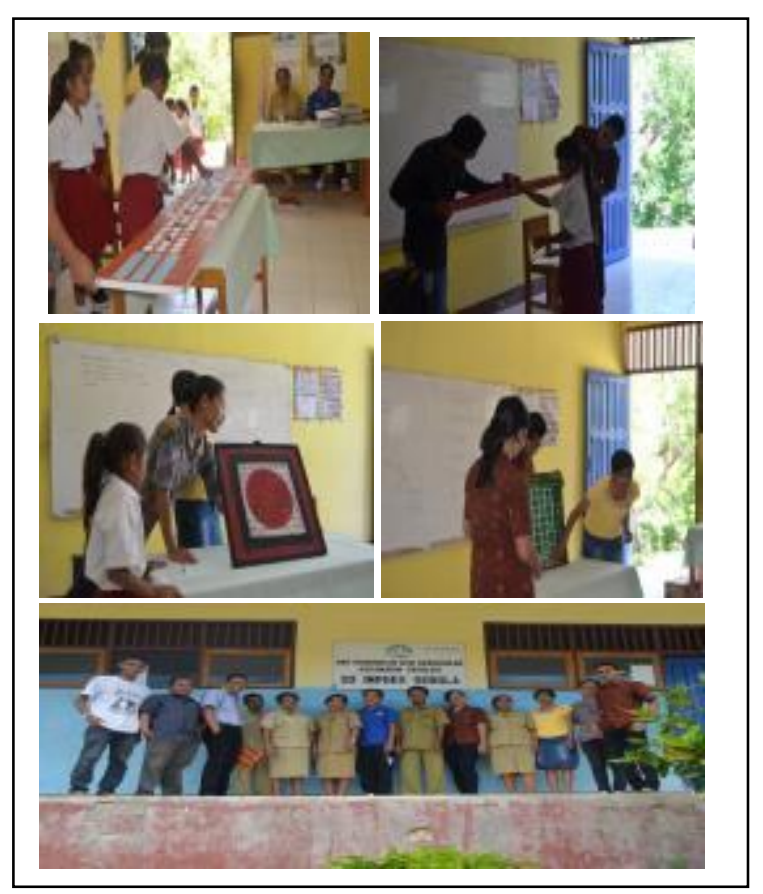

Gambar 1. Pelaksanaan Kegiatan Bersama Siswa Dan Guru-Guru

\section{Evaluasi}

Evaluasi digunakan untuk menyatakaan keberhasilan dari kegiatan yang dilakukan. 
Evaluasi dilaksanakan setelah kegiatan pelatihan dengan memberikan kuisioner kepada para peserta untuk kemudian dianalisis. Jawaban dari responden dapat dilihat pada tabel 2 .

Tabel 2. Hasil Jawaban Evaluasi Kegiatan Melalui Kuisioner

\begin{tabular}{|l|l|l|}
\hline \multirow{2}{*}{ No } & \multicolumn{2}{|c|}{ Evaluasi Kegiatan } \\
\cline { 2 - 3 } & \multicolumn{1}{|c|}{ Indikator } & Total Jawaban \\
\hline 1a & Sangat Paham & 11 \\
\hline 1b & Paham & 17 \\
\hline 1c & Kurang Paham & 0 \\
\hline 1d & Tidak Paham & 0 \\
\hline 2a & Sangat Bermanfaat & 20 \\
\hline 2b & Bermanfaat & 8 \\
\hline 2c & Kurang Bermanfaat & 0 \\
\hline 2d & Tidak Bermanfaat & 0 \\
\hline \multirow{3}{*}{3} & $\begin{array}{l}\text { Sebagian besar peserta mengatakan senang } \\
\text { dengan kegiatan ini serta sangat bermanfaat } \\
\text { bagi mereka. }\end{array}$ \\
\hline
\end{tabular}

Berdasarkan pelaksanaan kegiatan serta dilakukan evaluasi akhir untuk mengetahui tingkat keberhasilan secara keseluruhan terlihat adanya antusiasme dari masing-masing peserta untuk terlibat aktif dalam kegiatan yang ditunjukkan dengan keingintahuan dari masing-masing sehingga kegiatan yang dilaksanakan dapat berjalan sesuai dengan jadwal yang telah dibuat oleh tim pengabdian. Selain itu adanya interaksi dari peserta terutama untuk memahami lebih jauh berkaitan dengan konsep-konsep matematia seperti apa yang dapat dibuat dalam bentuk alat peraga matematika. Selain itu guru-guru dapat memahami cara pembuatan alat peraga serta penggunaanya dalam kegiatan pembelajaran. Hal ini sejalan dengan hasil pengabdian yang diungkapkan oleh
(Kho, Tyas, \& Cenderawasih, 2020) pelaksanaan kegiatan pengabdian namun perlu dilakukan pembenahan terhadap media alat peraga yang cocok digunakan sesuai dengan materi yang diajarkan.

\section{SIMPULAN}

Pelaksanaan kegiatan pemanfaatan alat peraga matematika sebagai media pembelajaran berjalan dengan lancar sehingga meningkatkan antusiasme dari peserta dengan memberikan berbagai macam respon positif, serta peserta dapat memahami dan menggunakan alat peraga matematika dalam memahami konsep.

\section{UCAPAN TERIMA KASIH}

Terimaksih kepada LPPM UNWIRA atas bantuan Dana Hibah yang diberikan kepada tim sehingga kegiatan pengabdian ini dapat berjalan dengan lancar serta tidak mengalami kendala pada saat pelaksanaan.

\section{DAFTAR PUSTAKA}

Azmi, S., Sripatmi, Subarina, S., Amrullah, \& Turmuzi, M. (2019). Pelatihan Pembuatan Alat Peraga Pembelajaran MatematikaUntuk Meningkatkan Profesionalisme Guru-Guru SD Gugus II Ampenau Utara. Jurnal Pendidikan Dan Pengabdian Masyarakat, 2(4), 427-432.

Binanguan, H. H., \& Hakim, A. R. (2016). Pengaruh Pengunaan Alat Jam Sudut Terhadap Hasil Belajar Matematika. JKPM, 1(2), 204-214.

Hutagaol, A. S. R., Nyama, H., \& Warkitin. (2019). Pengembangan Alat Peraga Papan Berpaku Matematika Kelas III SDN 29 Sungai Puang. J-PiMat, 1(2), 79-90. 
344 Pemanfaatan Alat Peraga Matematika sebagai Media Pembelajaran di SD Oebola Dalam Nusa Tenggara Timur - Yohanes O. Jagom, Irmina V. Uskono, Aloysius J. Fernandez

DOI : https://doi.org/10.31004/abdidas.v1i5.73

Kho, R., Tyas, D. K. N., \& Cenderawasih, U. (2020). Pelatihan Pembuatan Alat Peraga Matematika bagi Guru-Guru SD YPK Yoka Baru Waena Kota Jayapura. Jurnal Ilmu Sosial Dan Pendidikan, 4(2), 97-100.

Murdiyanto, T., \& Mahatma, Y. (2014). Pengembangan alat Peraga Matematika Untuk Meningkatkan Minat dan Motivasi Belajar Matematika Siswa sekolah dasar. Jurnal Sarwahita, 11(1), 38-43.

Nasaruddin. (2015). Media Dan Alat Peraga Dalam Pembelajaran Matematika. Al Khwarizmi : Jurnal Pendidikan Matematika Dan Ilmu Pengetahuan Alam, 3(21-30). Retrieved from http://ejournal.iainpalopo.ac.id/index.php/alkhwarizmi/article/view/232/198

Rusmawati. (2017). Penggunaan Alat Peraga Langsung Pada Pembelajaran Matematika Dengan Materi Pecahan Sederhana Untuk Meningkatkan Hasil Belajar Matematika. Jurnal Sosial, Pendidikan, Humaniora, 3(2), 307-314.

Sa'o, S., Naja, F. Y., \& Irfan, A. (2019). Penerapan Pembelajaran Dengan Menggunakan Alat Peraga Pada Pembelajaran Matematika SMP. $A l$ Khwarizmi : Jurnal Pendidikan Dan Pembelajaran Matematika, 3(1), 65-73.

Susanah, S., Ismail, I., \& Astuti, Y. P. (2016). Pelatihan Pembuatan Alat Peraga Pembelajaran Matematika Di SDN Pakis V Surabaya. Jurnal ABDI, I(2), 156. https://doi.org/10.26740/ja.v1n2.p156-161

Suwardi, Firmiana, M. E., \& Rohayati. (2014). Pengaruh Penggunaan Alat Peraga Terhadap Hasil Pembelajaran Matematika Pada Anak Usia Dini. Al-Azhar Indonesia Seri Humaniora, 2(4), 297-305. 